\title{
The control of morph development in the parasitic nematode Strongyloides ratti
}

\author{
S. C. Harvey ${ }^{\dagger} \dagger$, A. W. Gemmill ${ }^{1}$ A. F. $\operatorname{Read}^{1}$ and M. E. Viney ${ }^{2 *}$ \\ ${ }^{1}$ Division of Biological Sciences, University of Edinburgh, West Mains Road, Edinburgh EH9 37T, UK \\ ${ }^{2}$ School of Biological Sciences, University of Bristol, Woodland Road, Bristol BSo 1UG, UK
}

\begin{abstract}
The parasitic nematode Strongyloides ratti has a complex life cycle. The progeny of the parasitic females can develop into three distinct morphs, namely directly developing infective third-stage larvae (iL3s), free-living adult males and free-living adult females. We have analysed of the effect of host immune status (an intra-host factor), environmental temperature (an extra-host factor) and their interaction on the proportion of larvae that develop into these three morphs. The results are consistent with the developmental decision of larvae being controlled by at least two discrete developmental switches. One is a sexdetermination event that is affected by host immune status and the other is a switch between alternative female morphs that is affected by both host immune status and environmental temperature. These findings clarify the basis of the life cycle of S. ratti and demonstrate how such complex life cycles can result from a combination of simple developmental switches.
\end{abstract}

Keywords: sex ratio; facultative sex; developmental switching

\section{INTRODUCTION}

Strongyloides ratti is a gastro-intestinal parasitic nematode of rats. It has a complex life cycle with both parasitic and free-living phases. The parasites, which are female only, reproduce by a functionally mitotic parthenogenesis (Viney 1994). Their progeny pass from the rat to the external environment, where subsequent development occurs. Here, the larval progeny can moult through two larval stages into directly developing infective third-stage larvae (iL3s). This is termed direct development. Alternatively, larval progeny can moult through four larval stages into free-living adult males and adult females. This is termed indirect development. Thus, the free-living phase of the life cycle has three alternative morphs: freeliving males, free-living females and directly developing iL3s. The free-living adults reproduce by conventional sexual reproduction and all their progeny develop into indirectly developing iL3s (Viney et al. 1993). The iL3s that have developed by both the direct and the indirect routes infect rats by skin penetration.

A number of factors are known to affect the proportion of larvae that develop by the direct or indirect route. Development by these routes has been determined by measuring the proportion of larvae that develop directly into iL3s (Viney et al. 1992). These observations have shown that the proportion of larvae that develop into directly developing iL3s varies between different isofemale lines (Viney et al. 1992), is affected by the temperature at which developing larvae are maintained (Premvati 1958; Nwaorgu 1983; Viney 1996), depends on the immune status of the host (Gemmill et al. 1997) and can be altered by selection (Viney 1996). Host immune status is an intra-host factor and thus can act on both the parasitic females and their progeny as they pass from the host. Environmental temperature is an extra-

\footnotetext{
*Author for correspondence (mark.viney@bristol.ac.uk).

$\dagger$ Present address: Institute of Aquaculture, University of Stirling, Stirling FK9 4LA, UK.
}

host factor that can act only on free-living larvae passed out of the host.

Studies with a number of species of Strongyloides have found that manipulation of extra-host environmental conditions affected the proportion of larvae that developed into directly developing iL3s and free-living females, but that the proportion of larvae that developed into freeliving males was not affected. Thus, for example with $S$. ratti, changes in the concentration of linoleic acid (Minematsu et al. 1989) or of carbon dioxide or oxygen (Taylor \& Weinstein 1990) in faecal cultures changed the proportions of free-living females and directly developing iL3s, but did not affect the proportion of free-living males that developed. Analogous observations using other environmental manipulations have been made for Strongyloides stercoralis (Shiwaku et al. 1988), Strongyloides ransomi (Moncol \& Triantaphyllou 1978), Strongyloides papillosus (Nwaorgu 1983) and Strongyloidesplaniceps (Arizono 1976).

These observations have led to the hypothesis that the progeny of parasitic females are genetically male or female and that male progeny develop into free-living males only, while female progeny develop either into directly developing iL3s or into free-living females. Thus, directly developing iL3s and free-living females are alternative female morphs. In this hypothesis, the proportion of larvae that develop into free-living males is unaffected by extra-host factors. Conversely, extra-host factors would affect the proportion of female larvae that develop into each of the alternative female morphs. This postulated life cycle for $S$. ratti is shown in figure 1 . This view of the life cycle is also consistent with the findings of the cytological studies of S.ratti, which have concluded that the diploid chromosome number of both the parasitic and free-living females is six while that of the free-living males is five (Nigon \& Roman 1952; Bolla \& Roberts 1968). These cytological studies have been supported by recent molecular studies that have counted the number of putative $\mathrm{X}$ chromosomes in the different morphs of the S. ratti life cycle. These found that parasitic and free-living females and iL3s had two $\mathrm{X}$ chromosomes, while free-living 
males had just one (S. C. Harvey and M. E. Viney, unpublished data).

This hypothesized life cycle (figure 1) has not been rigorously tested. In particular, these studies have not measured the effect of environmental manipulations on the total number of surviving worms and thus have not considered differential mortality as a source of the observed changes in the proportions of each morph that develop. In addition, many of these studies used parasite material prepared from faecal samples without determining whether this preparation had any effect on future development. For example, Taylor \& Weinstein (1990) collected eggs from the host gut and used these in axenic culture. These eggs represent only a subset of the whole developing larval population since S.ratti produces a mixture of eggs and first-stage larvae (Sandground 1925). Further, they found that in their axenic-culture regime, free-living adults took longer to develop and were smaller than worms from faecal cultures.

In the work presented here we test the hypothesized life cycle of $S$. ratti by analysing the effect of manipulation of intra- and extra-host factors (figure 1). We investigate how the effects of these factors change during an infection. We also investigate the interaction of these factors on the two hypothesized developmental switches. The findings clarify the developmental basis of the complex life cycle of S. ratti.

\section{MATERIAL AND METHODS}

\section{(a) Parasites and maintenance}

Parasite lines were maintained by serial passage in randomly bred, size-matched (100-150 g) female Wistar rats (Bantin \& Kingman, Hull, UK), which were also used in all experiments unless otherwise stated. Food and water were provided ad libitum. All infections were prepared by dilution in saline $(0.8 \% \mathrm{w} / \mathrm{v}$ $\mathrm{NaCl}$ ) and administered by subcutaneous injection unless otherwise stated. Faeces from experimental animals were collected and cultured as described by Viney et al. (1992) and maintained for three days at $19^{\circ} \mathrm{C}$ or two days at $25^{\circ} \mathrm{C}$ when the proportion of each morph (directly developing iL3s, free-living males and freeliving females) and the total number of worms present in faecal cultures was determined, as described by Viney (1996). For experiments where incubation temperature was an experimental treatment (see $\S 2(\mathrm{~b})(\mathrm{i}, \mathrm{iii})$ ) an equal number of cultures from each animal were maintained at $19^{\circ} \mathrm{C}$ and $25^{\circ} \mathrm{C}$.

\section{(b) Experiments}

\section{(i) Incubation temperature}

Twelve rats were infected with 500 indirectly developing iL3s of isofemale line ED321 Heterogonic, which is derived from isofemale line ED5 Heterogonic (Viney 1996). Faeces were collected on day 8 post-infection (p.i.), cultured, and maintained at $19^{\circ} \mathrm{C}$ and $25^{\circ} \mathrm{C}$.

\section{(ii) Host immune status}

These experiments were described previously (Gemmill et al. 1997) but here we present a new analysis of other aspects of these data. Experimental methods are, therefore, only briefly outlined. For all immunological treatments faecal cultures were maintained $19^{\circ} \mathrm{C}$.

\section{Previous exposure}

Groups of three animals were infected subcutaneously with 0 (naive, control animals), 1, 10 or 50 iL3s of isofemale line ED5

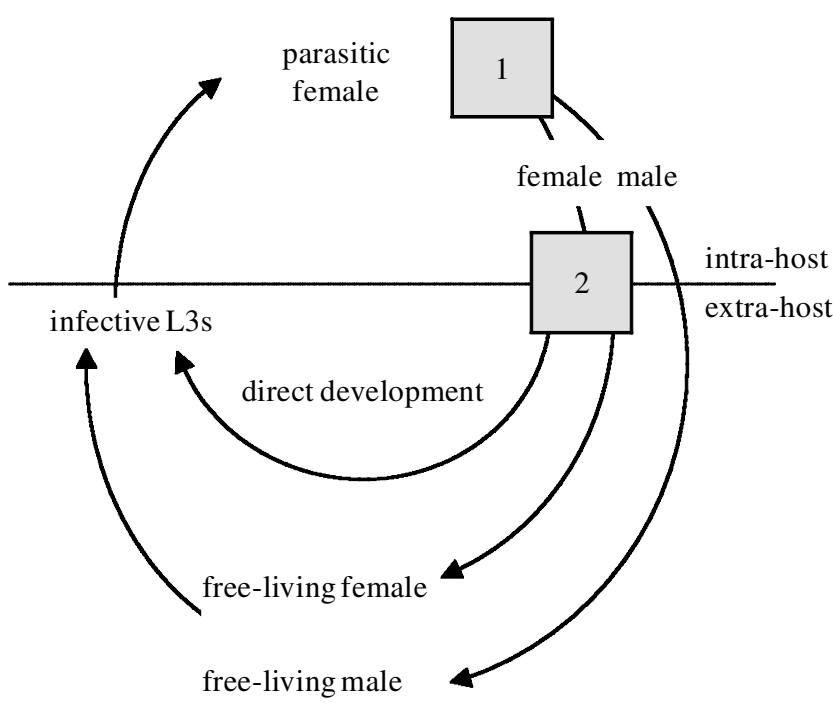

Figure 1. Postulated life cycle of Strongyloides ratti with two discrete developmental switches, shown as grey boxes: 1, a sex determination event; 2 , a female-only developmental switch.

Heterogonic. Infections were monitored to confirm patency where appropriate. On days 27 and 28 p.i. all animals were treated with $0.11 \mathrm{ml}$ of a $17.6 \% \mathrm{w} / \mathrm{v}$ thiabendazole suspension (Thibenzole; MSD AGVET, Hoddesdon, Herts, UK) by oral intubation to clear remaining parasites. On day 35 p.i. all animals were challenged by subcutaneous infection with 250 iL3s of ED5 Heterogonic.

\section{Immune suppression}

Congenitally hypothymic (nude) rats $(n=4)$ (homozygous for HsdHan:NZNU-rnu ${ }^{\mathrm{N}}$ ) and heterozygous, thymus intact, control animals $(n=4)$ (HsdHan:NZNU-rnu ${ }^{\mathrm{N}} /+$ ) (Harlan, Bicester, UK) were infected with 500 iL3s of isofemale line ED5 Heterogonic.

Three rats were exposed to $6.5 \mathrm{~Gy}$ from a ${ }^{137}$ caesium $\gamma$ emitting source three days prior to infection with 500 iL3s of ED5 Heterogonic. Three non-irradiated control animals were treated comparably.

Six rats were infected with 500 iL3s of ED5 Heterogonic and monitored from day 6 p.i. onwards. On day 8 p.i., animals were arbitrarily assigned to treatment or control groups $(n=3$ in each). Experimental animals were treated with $10 \mathrm{mg}$ betamethasone (Betsolan; Pitman Moore, Co. Wicklow, Eire) per kilogram mean body weight by subcutaneous injection from day 8 to day 13 p.i. inclusive. Control animals received analogous, sham inoculations of sterile saline. The proportions of larvae that developed into each morph were determined from faeces collected from day 9 to day 17 p.i., to allow for the delay in the effect of the corticosteroid treatment (Gemmill et al. 1997).

\section{(iii) Interaction of host immune status and incubation temperature} Immune suppression

Congenitally hypothymic rats $(n=3)$ (homozygous for HsdHan:NZNU-rnu ${ }^{\mathrm{N}}$ ) and heterozygous, thymus intact, control animals $(n=3)$ (HsdHan:NZNU-rnu ${ }^{\mathrm{N}} /+$ ) (Harlan) were infected with 500 iL3s of isofemale line ED5 Homogonic (Viney 1996).

\section{Previous exposure}

Three rats were infected with 10 iL3s of ED321 Heterogonic and monitored to confirm patency. Three control animals were 
treated comparably but not infected. On days 27 and 28 p.i. all animals were treated with $0.11 \mathrm{ml}$ of a $17.6 \% \mathrm{w} / \mathrm{v}$ thiabendazole suspension (Thibenzole; MSD AGVET) to clear remaining parasites, which was confirmed by faecal monitoring. On day 35 p.i. all animals were challenged by infection with 500 iL3s of ED5 Homogonic.

\section{(c) Statistical analysis}

From the hypothesis that the progeny of parasitic females are genetically male or female, and that male progeny develop into free-living males only, while female progeny develop either into directly developing iL3s or into free-living females (figure 1), the key variables under investigation were (i) the proportion of larvae that developed into free-living males (this was calculated as the number of larvae that developed into free-living males divided by the total number of worms counted); and (ii) the proportion of putative female larvae that developed into freeliving females (this was calculated as the number of larvae that developed into free-living females divided by [the number of larvae that developed into free-living females + the number that developed into directly developing iL $3 \mathrm{~s}]$ ).

For the experiments described in $\S 2$ (b) (iii), the differences in these proportions between the two temperature treatments was calculated as the proportion at $25^{\circ} \mathrm{C}$ minus the proportion at $19^{\circ} \mathrm{C}$. The differences in the proportions at $19^{\circ} \mathrm{C}$ and $25^{\circ} \mathrm{C}$ are a measure of the relative effect of the two incubation temperatures on larval development. Alternatively, the differences in the proportions can be considered as a measure of the sensitivity of developing larvae to temperature. For the experiment described in $\S 2(\mathrm{~b})(\mathrm{i})$, the proportion of all worms that developed into each morph (free-living males, free-living females and directly developing iL3s) was used. All proportions, but not differences in proportions, were angular transformed prior to analysis. In all figures the values are back transformed.

The proportion of larvae that develop into different morphs change during the course of an infection in normal animals (Viney 1996; Gemmill et al. 1997). To investigate the effects of the experimental manipulations on the rate of change through time of these proportions, or differences in proportions between different temperatures, the slopes of the ordinary least-squares regressions of the transformed proportions against time were calculated. These slopes, and where appropriate the mean proportionduring the course of an infection, were used as response variables. This avoided the difficulties of non-independence that arise from repeated measures of infection in an individual animal, since each animal appeared in an analysis just once. Frequently it was appropriate to ask whether these slopes were significantly different from zero. This was done with a onesample, two-tailed $t$-test. The effect of the experimental manipulations on these slopes, or on the mean proportion, were investigated by fitting a general linear model (GLM) with TREATMENT (e.g. immune suppression, previous exposure or control) and where relevant EXPERIMENT (e.g. method of immune suppression; see $\S 2$ (b)(ii)) and the TREATMENT $\times$ EXPERIMENT interaction. Throughout, reported $t$-values refer to one-sample $t$-tests and $F$-ratios to the GLMs.

\section{RESULTS}

\section{(a) Incubation temperature}

The proportion of larvae that developed into freeliving males did not differ significantly $\left(F_{1,11}=1.64\right.$, $p=0.23)$ between the $19^{\circ} \mathrm{C}$ and $25^{\circ} \mathrm{C}$ temperature treat-

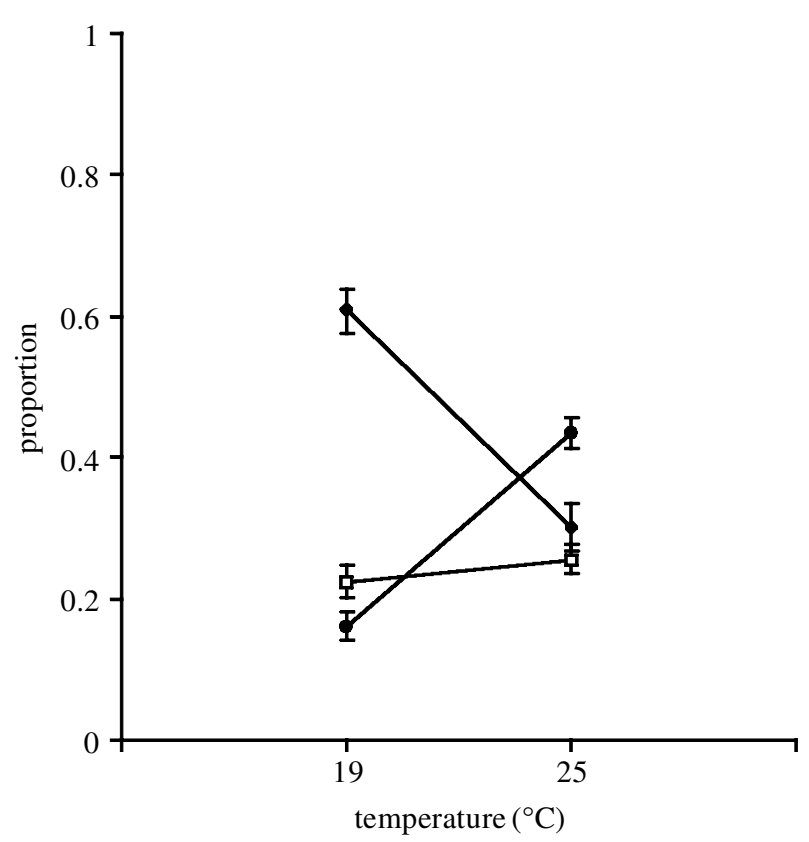

Figure 2. The mean proportions of larvae that developed into free-living males (open squares), free-living females (closed circles) and directly developing iL3s (closed diamonds) in faecal cultures maintained at $19^{\circ} \mathrm{C}$ and at $25^{\circ} \mathrm{C}$. Error bars are \pm 1 s.e.m.

ments (figure 2). In contrast, the proportions of larvae that developed into directly developing iL3s and into free-living females were significantly different $\left(F_{1,11}=0.8\right.$, $p<0.0001$ and $F_{1,11}=53.3, p<0.0001$, respectively). These differences were not due to differential survival of the morphs since the total number of worms that developed at $19{ }^{\circ} \mathrm{C}$ and at $25^{\circ} \mathrm{C}$ were not significantly different $\left(F_{1,11}=0.41, \quad p=0.53 ; \quad\right.$ mean \pm s.e.m. $=6640 \pm 875$ and $5940 \pm 624$, respectively).

A difference of 2000 worms between the two incubation temperatures would be required to generate the observed difference in the proportion of iL3s. Standard power calculations (Armitage \& Berry 1987) show that had such a difference occurred there was a probability of over $99.9 \%$ of detecting it as significant. Indeed, there was a $90 \%$ probability of detecting as significant a difference in worm number of half this. Thus, the observed effect of temperature on the proportion of each morph that develops is not a trivial consequence of differences in the total number of worms that develop at the two temperatures.

\section{(b) Host immune status}

\section{(i) Previous exposure}

The proportion of larvae that developed into freeliving males increased during the post-challenge period in all animals (figure $3 a$ ). The rate of this increase was not affected by host previous exposure $\left(F_{3,7}=0.46\right.$, $p=0.72$ ) but on average a greater proportion of larvae developed into free-living males in previously exposed animals, compared with control, naive animals $\left(F_{3,7}=15.5\right.$, $p=0.002$ ).

The proportion of female larvae that developed into free-living females also increased during the post-challenge period in all animals (figure $3 b$ ). The rate of this increase was greater for larvae from previously exposed animals, 

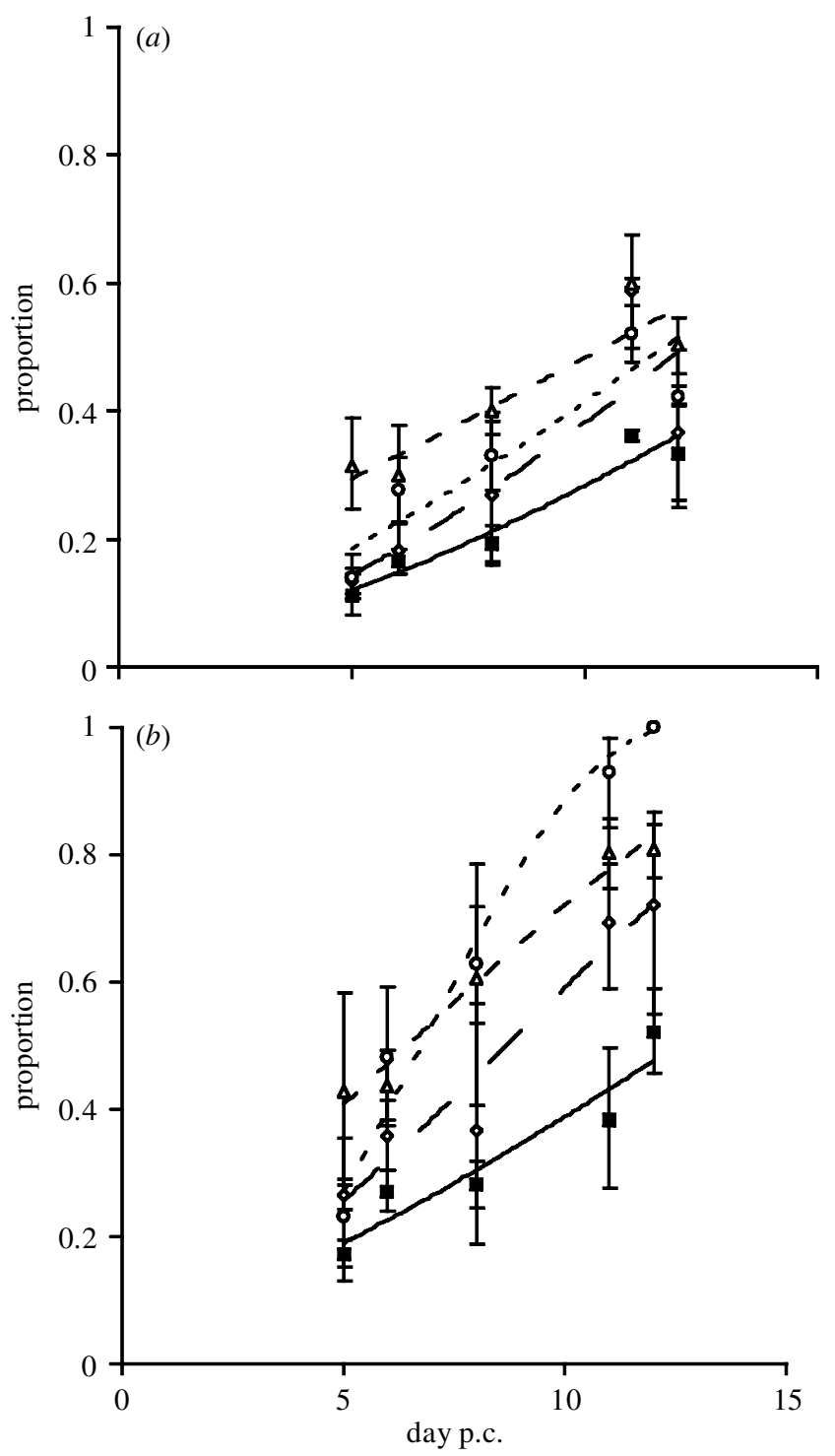

Figure 3. (a) The proportion of larvae that developed into free-living males and $(b)$ the proportion of female larvae that developed into free-living females for animals exposed to zero (control, naive animals) (closed squares), one (open diamonds), ten (open triangles) and 50 (open circles) iL3s plotted against days post-challenge (p.c.). Plotted values are means of three rats \pm 1 s.e.m. and best-fit regression lines fitted to angular-transformed proportions for all data from each group for animals exposed to zero (naive) (solid line), one (long dashes), ten (short dashes) and 50 (dots) iL3s.

compared with naive animals $\left(F_{3,7}=9.2, p=0.008\right)$ and on average a greater proportion of larvae developed into free-living females in previously exposed, compared with naive, animals $\left(F_{3,7}=6.07, p=0.023\right)$.

\section{(ii) Immune suppression}

Host immune suppression reduced the proportion of larvae that developed into free-living males over the course of an infection, compared with control animals (figure $4 a, c, e)$. The proportion of larvae that developed into free-living males increased during an infection in control animals $\left(t_{11}=11.21, p<0.0001\right)$ but there was no such increase in larvae passed from immunosuppressed animals $\left(t_{9}=1.07, \quad p=0.31 ; \quad\right.$ TREATMENT effect $F_{1,14}=52.54$,
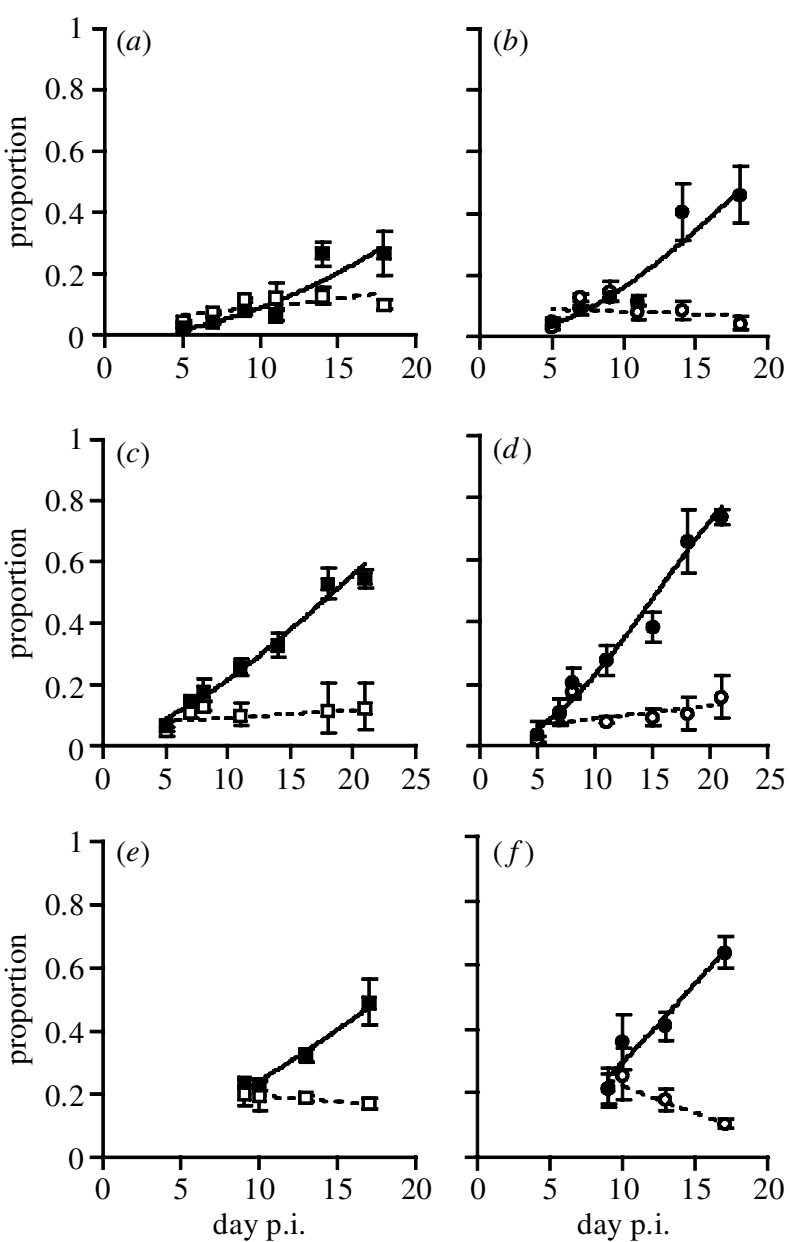

Figure 4. The proportion of larvae that developed into free-living males in $(a)$ hypothymic, $(c)$ irradiated and (e) corticosteroid immune-suppression experiments and the proportion of female larvae that developed into free-living females in $(b)$ hypothymic, $(d)$ irradiated and $(f)$ corticosteroid immune-suppression experiments plotted against days post-infection (p.i.). Plotted values are means of three rats \pm 1 s.e.m., except $(a)$ and $(b)$ where values are the means of four rats. Open symbols indicate immunosuppressed animals and closed symbols indicate control animals. Best-fit regression lines fitted to angular-transformed proportions for all data from each group are shown for the immunosuppressed (dotted line) and control (solid line) animals.

$p<0.001)$. This effect of immune suppression was independent of the method of immune suppression (TREATMENT $\times$ EXPERIMENTeffect $F_{2,14}=1.16, p=0.34$ )

Host immune suppression also reduced the proportion of larvae that developed into free-living females over the course of an infection, compared with control animals (figure $4 b, d, f$ ). The proportion of larvae that developed into free-living females increased during an infection in control animals $\left(t_{11}=11.73, p=0.0001\right)$ but there was no such increase in larvae passed from immunosuppressed animals $\left(t_{9}=1.05, \quad p=0.32 ; \quad\right.$ TREATMENT effect $F_{1,14}=77.73$, $p<0.001)$. This effect of immune suppression was independent of the method of immune suppression (TREATMENT $\times$ EXPERIMENT effect $F_{2,14}=1.90, p=0.19$ )

The proportions of larvae that developed into the three morphs were followed in the hypothymic rats until day 214 p.i. During this time, the proportion of larvae that developed into free-living males increased $\left(t_{3}=5.0\right.$, 

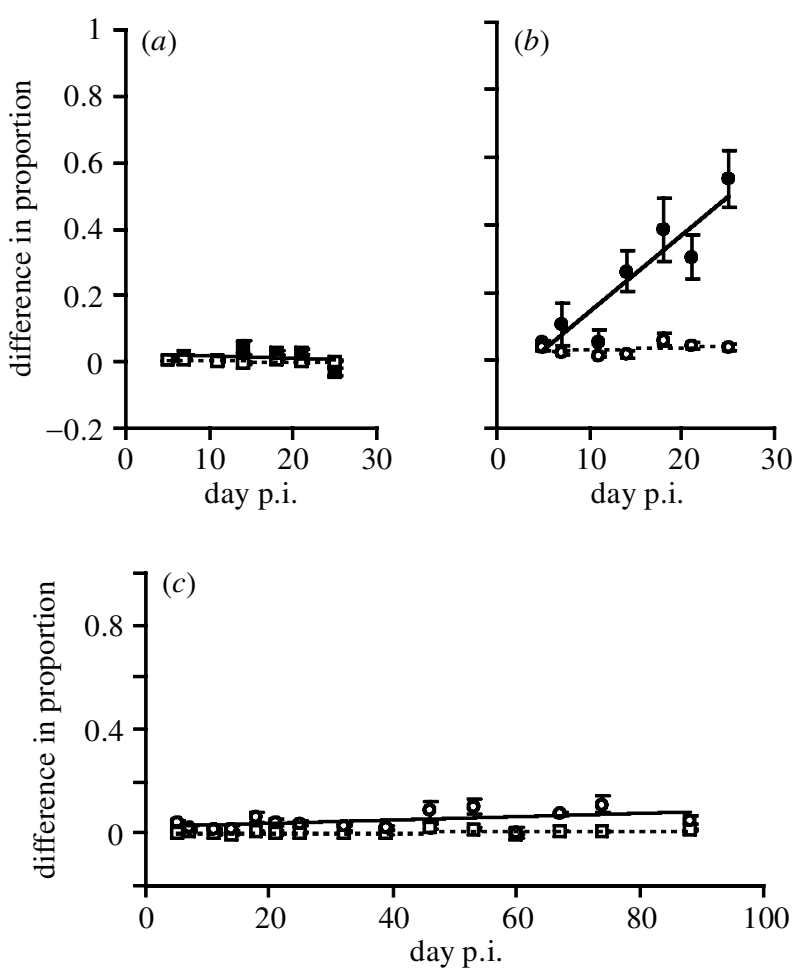

Figure 5. The difference in $(a)$ the proportion of larvae that developed into free-living males and $(b)$ the proportion of female larvae that developed into free-living females in faecal cultures maintained at $19^{\circ} \mathrm{C}$ and at $25^{\circ} \mathrm{C}$ in hypothymic (open symbols) and intact, control animals (closed symbols); best-fit regression lines for all data from each group are shown for the hypothymic (dotted line) and control (solid line) animals. $(c)$ The difference in the proportion of free-living males (squares) and free-living females (circles) in hypothymic animals until day 88 post-infection (p.i.); best-fit regression lines for all data are shown for the proportion of free-living males (dotted line) and free-living females (solid line). Plotted values are means of three rats \pm 1 s.e.m.

$p=0.015)$ but the proportion of female larvae that developed into free-living females did not $\left(t_{3}=2.51, p=0.086\right)$ (data not shown).

\section{(c) Interaction of host immune status and incubation temperature \\ (i) Immune suppression}

The difference in the proportion of larvae that developed into free-living males at $19^{\circ} \mathrm{C}$ and at $25^{\circ} \mathrm{C}$ did not vary during an infection in the control, intact animals or in the hypothymic animals (figure $5 a)\left(t_{5}=0.265, p=0.80\right.$; TREATMENT effect $\left.F_{1,4}=0.38, p=0.57\right)$.

In contrast, the temperature sensitivity of the switch between alternative female morphs increased during an infection in the intact animals $\left(t_{2}=5.69, p=0.03\right)$, but not in the hypothymic animals (figure $5 b)\left(t_{2}=0.0, p=0.99\right.$; TREATMENT effect $\left.F_{1,4}=29.6, p=0.006\right)$.

The proportions of larvae that developed into each of the three morphs was followed in the hypothymic rats until day 88 p.i. During this time, the temperature sensitivity of the switch between alternative female morphs increased (figure $5 c)\left(t_{2}=4.38, p=0.048\right)$, but there was no such effect on the proportion of larvae that developed into free-living males.
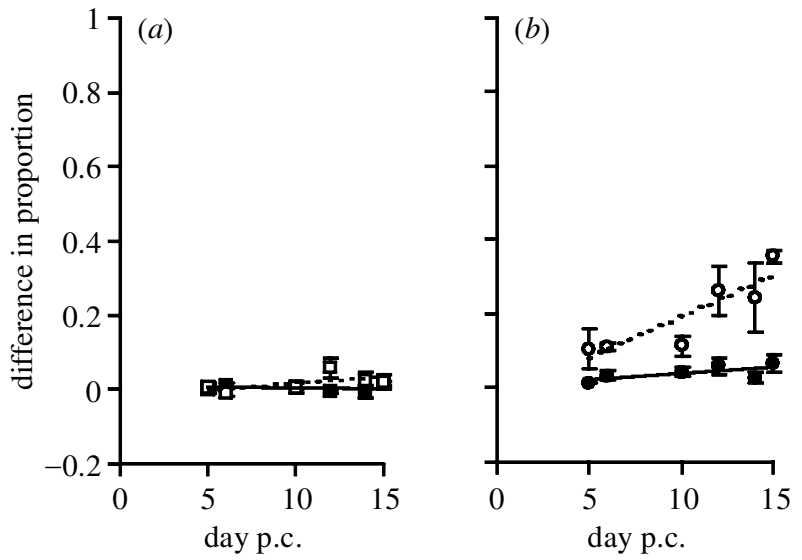

Figure 6. The difference in $(a)$ the proportion of larvae that developed into free-living males and $(b)$ the proportion of female larvae that developed into free-living females in faecal cultures maintained at $19^{\circ} \mathrm{C}$ and at $25^{\circ} \mathrm{C}$ in previously exposed (open symbols) and control, naïve animals (closed symbols). Plotted values are means of three rats \pm 1 s.e.m. Best-fit regression lines for all data from each group are shown for the previously exposed (dotted line) and control (solid line) animals.

\section{(ii) Previous exposure}

The difference in the proportions of larvae that developed into free-living males at $19{ }^{\circ} \mathrm{C}$ and at $25^{\circ} \mathrm{C}$ did not vary during an infection in the previously exposed animals or in the control, naive animals (figure $6 a$ ) $\left(t_{5}=1.41, p=0.22\right.$; TREATMENT $\left.F_{1,4}=5.76, p=0.08\right)$.

In contrast, the temperature sensitivity of the switch between alternative female morphs increased during an infection in the previously exposed animals $\left(t_{2}=6.80\right.$, $p=0.02$ ) but not in the control animals (figure $6 b$ ) $\left(t_{2}=2.50, p=0.13\right.$; TREATMENT $\left.F_{1,4}=219, p=0.001\right)$.

\section{DISCUSSION}

Previous studies have suggested that in the life cycle of S. ratti the progeny of the parasitic female were genetically male or female and that male progeny developed into free-living males only, while female progeny could develop into free-living females or directly into iL3s (figure 1). We have investigated this hypothesis by manipulation of intra- and extra-host factors. Manipulation of the incubation temperature of faecal cultures did not alter the proportion of worms that developed into free-living males. In contrast, when a greater proportion of larvae developed into free-living females, fewer developed into directly developing iL3s (figure 2). Thus, development of larvae into free-living females, but not into free-living males, is affected by temperature. This female developmental switch represents a form of phenotypic plasticity termed a developmental conversion, a threshold response that leads to a developmental switch between different phenotypes (Smith-Gill 1983).

It has previously been shown for S.ratti that host immune status affects the proportion of larvae that develop into sexually reproducing free-living adult forms, with development into these forms favoured in hosts mounting an immune response (Gemmill et al. 1997). These observations were made by considering the 
developmental choice in S.ratti as a switch between 'asexual' (directly developing iL3s) and 'sexual' (freeliving males and females) development. Analysis of the effect of host immune status on the two developmental switches (figure 1) shows how this arises.

Host immune status affects the proportion of larvae that develop into free-living males. In naive animals that are immunologically intact, the proportion of larvae that develop into males increases as an infection progresses (figures $3 a, 4 a, c, e)$. In animals that have been previously exposed, and thus have an enhanced immune response, more larvae develop into free-living males, at any point during an infection, than in naive animals (figure $3 a$ ). In the reverse situation, in immunologically impaired animals, there is no change in the proportion of freeliving males during an infection (figure $4 a, c, e$ ).

Host immune status also affects the proportion of female larvae that develop into free-living females and directly developing iL3s. In naive, immunologically intact animals this proportion increases during an infection (figure $3 b, 4 b, d, f$ ). In animals that have an enhanced immune response due to previous exposure, a greater proportion of female larvae develop into free-living females compared with control animals (figure $3 b$ ). In the reverse situation, in immunologically impaired animals, there is no change in the proportion of free-living females during an infection (figure $4 b, d, f$ ).

Combined, these observations show that the two developmental switches are affected by host immune status. This is in contrast to incubation temperature, which only affects the female developmental switch. Overall, these results show that as a host mounts an immune response a greater proportion of larvae develop into free-living males and that a greater proportion of female larvae develop into free-living females. This explains the developmental basis of the observed switch from 'asexual' to 'sexual' development in hosts mounting an immune response reported by Gemmill et al. 1997.

These results are consistent with the hypothesized life cycle (figure 1) in which the progeny of the parasitic female are genetically male and female, where male progeny develop into free-living males only, while female progeny can develop into free-living females or directly into iL3s. Cytological studies in S. ratti (Nigon \& Roman 1952; Bolla \& Roberts 1968) have found different numbers of chromosomes in free-living males and females. Similar studies in S. ransomi and S.papillosus have suggested that sex determination in these species occurs by an XX/XO, female/male, mechanism (Triantaphyllou \& Moncol 1977). Molecular studies of putative X chromosomes in S.ratti are also consistent with this (S. C. Harvey and M. E. Viney, unpublished data). Thus, the determination of male and female progeny of the parasitic females (figure 1) is very likely to be determined chromosomally. The proportion of larvae that develop into freeliving males is therefore a measure of this chromosomal sex ratio.

We hypothesize that this chromosomal sex ratio is controlled by the parasitic female. This stage is affected by intra-host factors only. In the free-living nematode Caenorhabditis elegans sex is genetically determined. XO males are produced by XX hermaphrodites as a result of a rare spontaneous $\mathrm{X}$ chromosome non-disjunction during meiosis (Hodgkin et al. 1979; Broverman \& Meneely 1994). The rate of this non-disjunction, and hence the rate of male production, increases with the age of the parent hermaphrodite (Goldstein \& Curtis 1987). In S.ratti, the chromosomal sex ratio (measured as the proportion of free-living males) becomes more male biased in the presence of a host immune response. Reproduction of the parasitic female of $S$. ratti is by a functionally mitotic parthenogenesis (Viney 1994). XO male progeny could therefore be generated by $\mathrm{X}$ chromosome non-disjunction during this mitosis. This allows the intriguing possibility that in $S$. ratti the host immune response affects the rate of $\mathrm{X}$ chromosome non-disjunction, presumably via the parasitic female. The effects of age on C. elegans and of host immune response on $S$. ratti are apparently analogous with respect to changes in sex ratio. In addition, long-term S. ratti infections in hypothymic rats do become more male biased, also suggesting an analogous effect of parental age on chromosomal sex ratio of the progeny in both these species. However, the observation that age-matched parasitic females of S.ratti in control and immunologically manipulated animals produce progeny of different sex ratios shows that host immune status is the dominant affector of the S.ratti sex ratio.

Temperature and host immune response affect the switch between alternative female morphs, with development into free-living females favoured at higher temperatures and by a host immune response. We investigated the effects of the interaction of these factors on the two developmental switches. The switch between free-living females and directly developing iL3s becomes more temperature sensitive as an infection progresses (figure $5 b$ ). In immunologically impaired animals there is no change (figure $5 b$ ). In animals with an enhanced immune response the temperature sensitivity is also enhanced (figure $6 b$ ). This, therefore, shows that the temperature sensitivity of the female switch is dependent on the immune status of the host from which the larvae were passed. However, in old infections (and hence in old parasitic females) in immunologically impaired, hypothymic animals this switch does become more temperature sensitive (figure $5 c$ ).

In $S$. stercoralis the switch between alternative female morphs requires the presence of two amphidial (paired anterior sensory structures) neurons in the first-stage larval progeny of parasitic females (Ashton et al. 1998). Larvae in which two pairs of amphidial neurons (ASF and ASI) were ablated with a laser microbeam developed into directly developing iL3s, whereas untreated larvae or larvae in which only ASF or ASI was ablated developed into freeliving females. If, as is likely, there is similar control of the female switch in $S$. ratti these amphidial neurons are likely to be the route by which the intra- and/or extra-host factors that affect the female developmental switch are sensed by developing larvae. This control is analogous to the amphidial neuronal control of the alternative dauer development route in C.elegans (Riddle \& Albert 1997). The factors that affect dauer development in C. elegans are chemical factors (food availability, measured as the concentration of a carbohydrate-like substance and population density, measured as the concentration of a constitutively expressed dauer pheromone) and temperature. By analogy, in Strongyloides spp. the measurement of host immune status 
may be by direct sensation of effector, or other intermediary, molecules of the host immune response.

The factors that affect the developmental switches of the $S$. ratti life cycle can suggest the selective factors maintaining the existence of the developmental switches in the life cycle. The effect of temperature on development may be an ecological adaptation in which temperature is used as a seasonal cue that may, for example, predict the probability of survival of free-living females or of encountering a new host. Equally, the effect of host immune status on development may be an adaptation that may predict the probability of encountering a susceptible host (Gemmill et al. 1997). The reason for the interaction of temperature and host immune status on the female switch is not immediately obvious. One possibility is that this arrangement may allow the coordinated development of free-living males and females. A consequence of the increased temperature sensitivity of the female switch in larvae passed from immune hosts is that at any temperature such larvae are more likely to develop into free-living females than into directly developing iL3s. An enhanced immune response also favours the development of freeliving males. Thus, larvae passed from immune animals are more likely to develop into a free-living generation of adult males and females. These hypotheses make testable predictions that now require testing.

We thank A. Buckling, N. Colegrave and M. Mackinnon for discussion and Y. Bisset and C. Wilkes and the animal-house staff in Edinburgh and Bristol for technical assistance. S.C.H. and A.W.G. were in receipt of Biotechnology and Biological Sciences Research Council (BBSRC) and Natural Environment Research Council studentships, respectively. A.F.R. and M.E.V. were supported by a BBSRC Advanced Research Fellowship and a Medical Research Council (MRG) Career Development Award, respectively. This work was supported by a grant from The Royal Society, the BBSRG and the MRG.

\section{REFERENCES}

Arizono, N. 1976 Studies on the free-living generation of Strongyloidesplaniceps Rogers 1943. I. Effects of quantity of food and population density on the developmental types. $7 p n$. $f$. Parasitol. 25, 274-282.

Armitage, P. \& Berry, G. 1987 Statistical methods in medical research. Oxford, UK: Blackwell.

Ashton, F. T., Bhopale, V. M., Holt, D., Smith, G. \& Schad, G. A. 1998 Developmental switching in the parasitic nematode Strongyloides stercoralis is controlled by the ASF and ASI amphidial neurons. 7. Parasitol. 84, 691-695.

Bolla, R. I. \& Roberts, L. S. 1968 Gametogenesis and chromosomal complement in Strongyloides ratti (Nematoda: Rhabdiasoidea). F. Parasitol. 54, 849-855.

Broverman, S. A. \& Meneely, P. M. 1994 Meiotic mutants that cause a polar decrease in recombination on the $\mathrm{X}$ chromosome in Caenorhabditis elegans. Genetics 136, 119-127.
Gemmill, A. W., Viney, M. E. \& Read, A. F. 1997 Host immune status determines sexuality in a parasitic nematode. Evolution 51, 393-401.

Goldstein, P. \& Curtis, M. 1987 Age-related changes in the meiotic chromosomes of the nematode Caenorhabditis elegans. Mech. Age. Dev. 40, 115-130.

Hodgkin, J., Horvitz, H. R. \& Brenner, S. 1979 Nondisjunction mutants of the nematode Caenorhabditis elegans. Genetics 91, $67-94$.

Minematsu, T., Mimori, T., Tanaka, M. \& Tada, I. 1989 The effect of fatty acids on the developmental direction of Strongyloides ratti first-stage larvae. F. Helminthol. 63, 102-106.

Moncol, D. J. \& Triantaphyllou, A. C. 1978 Strongyloides ransomi: factors influencing the in vitro development of the free-living generation. F. Parasitol. 64, 220-225.

Nigon, V. \& Roman, E. 1952 Le déterminisme du sexe et le développement cyclique de Strongyloides ratti. Bull. Biol. Fr. Belg. 86, 404-448.

Nwaorgu, O. C. 1983 The development of the free-living stages of Strongyloidespapillosus. I. Effect of temperature on the development of the heterogonic and homogonic nematodes in faecal cultures. Vet. Parasitol. 13, 213-223.

Premvati 1958 Studies on Strongyloides of primates. II. Factors determining the 'direct' and 'indirect' mode of life. Can. 7 . Zool. 36, 185-195.

Riddle, D. L. \& Albert, P. S. 1997 Genetic and environmental regulation of dauer larva development. In C.elegans, vol. 2 (ed. D. L. Riddle, T. Blumenthal, B. Myer \& J. R. Priess), pp. 739-768. Cold Spring Harbor monograph series 33. New York: Cold Spring Harbor Laboratory Press.

Sandground, J. H. 1925 Speciation and specificity in the nematode genus Strongyloides. F. Parasitol. 12, 59-82.

Shiwaku, K., Chigusa, Y., Kadosaka, T. \& Kaneko, K. 1988 Factors influencing development of free-living generations of Strongyloides stercoralis. Parasitology 97, 129-138.

Smith-Gill, S. J. 1983 Developmental plasticity: developmental conversion versus phenotypic modulation. Am. Zool. 23, 47-55.

Taylor, K. A. \& Weinstein, P. P. 1990 The effect of oxygen and carbon dioxide on the development of the free-living stages of Strongyloides ratti in axenic culture. 7. Parasitol. 76, 545-551.

Triantaphyllou, A. C. \& Moncol, D. J. 1977 Cytology, reproduction and sex determination of Strongyloides ransomi and S.papillosus. 7. Parasitol. 63, 961-973.

Viney, M. E. 1994 A genetic analysis of reproduction in Strongyloides ratti. Parasitology 109, 511-515.

Viney, M. E. 1996 Developmental switching in the parasitic nematode Strongyloides ratti. Proc. R. Soc. Lond. B 263, 201-208.

Viney, M. E., Matthews, B. E. \& Walliker, D. 1992 On the biological and biochemical nature of cloned populations of Strongyloides ratti. 7. Helminthol. 66, 45-52.

Viney, M. E., Matthews, B. E. \& Walliker, D. 1993 Mating in the nematode parasite Strongyloides ratti: proof of genetic exchange. Proc. R. Soc. Lond. B 254, 213-219.

As this paper exceeds the maximum length normally permitted, the authors have agreed to contribute to production costs. 